\title{
Patent Litigation when Innovation is Cumulative
}

\author{
Gerard Llobet \\ CEMFI
}

Working Paper No. 0102

January 2001

I thank Hugo Hopenhayn for his help and advice. This paper is partially based on the previous manuscript "Patent Design under the Threat of Litigation", in which I benefited from comments by Jeff Campbell, Susanna Esteban, Josh Lerner, Michael Manove, Matt Mitchell, Suzanne Scotchmer and Andrzej Skrzypacz. As usual, all errors are my own. Updated versions will be available at http://www.cemfi.es/ llobet. (Email address: llobet@cemfi.es).

CEMFI, Casado del Alisal 5, 28014 Madrid, Spain www.cemfi.es 


\begin{abstract}
This paper studies the effect of litigation as a way to enforce patents when firms hold private information. A structure to the legal system is provided, allowing a better understanding of the settlement and litigation decisions taken by enterpreneurs. The model is broadly consistent with recent empirical evidence. We show that the optimal license consists of a fixed fee and no royalties and that in some cases too much protection might be detrimental to the patentholder. We finally compare different legal systems and their effect on innovation and litigation.
\end{abstract}

JEL classification: D23, K41, 034.

Keywords: Patent Litigation, Licensing, Contracts. 


\section{Introduction}

Patents are imperfect assignments of property rights. The uncertainty surrounding the innovation process usually does not allow a precise specification of the range of innovations covered, provoking extensive infringement of these rights. These unavoidable disputes have made of litigation an integral part of the patent system, with important consequences for the incentives to innovate and patent.

The cost of this legal system constitutes an important social burden. In the U.S., from October 1996 to September 1997, 1,530 lawsuits involving patents were reported, although the number of processes is much higher. ${ }^{1}$ It has been estimated that the annual legal costs can represent as much as $25 \%$ of firms' basic R\&D expenses. Moreover, there is an ongoing debate on whether the patent system should be reformed. It is a common belief that the requirements to patent are too weak, and as a result, litigation is mainly used to define the boundaries of the protection that firms obtain. Understanding the connection between intellectual property rights and the way they are enforced will permit us to assess on the direction of these changes.

Patents are also regarded as an engine for technological progress and growth. The legal system provides a threat that allows the patentee to partially deter future innovation or to obtain in other cases licensing fees for the right to use the patent. Because changes in the institutions affect the way the negotiation power is distributed, sequential innovation and growth strongly depend on the legal system.

A patent is a complex contract that has been modelled in the literature in multiple ways. One of its most controversial dimensions is what it is usually denoted as breadth or scope. In its simplest definition, breadth

\footnotetext{
${ }^{1}$ This data was published by the U.S. Patent and Trademark Office (1997). It does not take into account patent disputes that are settled before filing the suit. Lerner(1995) estimates using a sample of 530 patents awarded to firms in the biotechnology sector in Massachusetts that $6 \%$ of them were involved in a litigation process.
} 
specifies the competing products and processes that are covered by the patent. Although breadth is considered an essential component, the ambiguity of the concept has not allowed a general formulation. One of the main goals of this paper is to provide a framework that makes explicit the way in which the litigation process can influence the characteristics of a patent, which in turn, will have consequences for research, competition and growth.

We propose a positive way to define the scope of patents. Rather than thinking about which should be the implications of the protection they grant, we focus on how they are actually enforced. The existence of courts and their rulings can be interpreted as a way to aggregate the relevant features of a patent. Therefore, if a court rules against the competing firm, we can infer that her invention was in fact inside the scope covered by the patent.

We examine the decision faced by a firm with an innovation. By developing it, the profits obtained will depend not only on the quality of the idea but also on the legal environment, and especially on the protection that the patent guarantees against future research.

When a second firm decides to produce an invention in an area where some patents are already in place, it has some idea about how likely it is to infringe them, and if this is the case, how likely it is to succeed in court. Moreover, the incentives for the patent holder to settle or litigate the infringement must be taken into account before entering. If the expected return net of legal costs is positive there will be entry.

The new invention represents an improvement over the original good, but its magnitude is private information held by the firm. Since litigation is costly, the patentee might be interested in reaching a settlement and being compensated by the infringer instead of going to court. In many such settlements, the patentee renounces to litigate and licenses the innovation to the infringer. We consider the most common form of licensing: a fixed fee plus a royalty on sales. Since better infringers benefit more from going 
to court, any settlement proposed will only be accepted by the competitors with the worst ideas, while the rest will go to court.

An interesting implication of the model is that the optimal licensing agreement consists of a flat fee, without royalties. The reason is that this structure allows the patentee to discriminate among competitors of different qualities and provides incentives for better infringers to settle and accept the licensing offer.

The legal procedure is used as a mechanism to reveal some of the private information that firms hold. As a result, there is some litigation even when firms behave optimally, in spite of being an inefficient way to solve disagreements. If this process were free we could use it to disclose all the information and decide in a case by case basis, but of course, it is not free. Being this a long and expensive verification method, ${ }^{2}$ it deters entry of some competitors that would produce otherwise, while in other situations it also gives incentives to reach a settlement between the patent holder and potential infringers.

Litigation is also a way to postpone the costly definition of some aspects of patent protection until more information is available. When firms apply for a patent, most of the future uses of an invention are uncertain. The individualized decisions resulting from the legal process help to protect the patent holder while at the same time incentives are provided for sufficiently good competitors to appear.

Most of the previous papers consider the scope of a patent as being clearly distinguishable, making infringement evident. ${ }^{3}$ Such a setup makes the existence of litigation irrelevant. In reality, however, boundaries are rather blurry, this being the reason why courts are needed to assess whether an invention infringes an existing patent or not.

Our approach represents an important departure from previous models of patent litigation, such as Meurer (1989) and Aoki and Hu (1999) where the case of a pure imitator was considered. As shown by O'Donoghue,

\footnotetext{
${ }^{2}$ Lerner (1995) estimates the direct legal costs to be almost $\$ 1$ billion every year.

${ }^{3}$ Two remarkable exceptions are Waterson (1990) and Aoki and Hu (1999).
} 
et al. (1998), sequential innovation requires patents to protect not only against imitation but also to entitle to some claims on future research. Without them severe underinvestment would result.

When the protection is related to future uses of the invention, the definition of breadth becomes particularly difficult. In fact, the breadth of a patent is endogenously determined by the litigation technology. That is, whether or not an invention infringes a given patent is determined by the decisions taken by courts. Therefore patent breadth is related to how likely it is that the patent holder succeeds in the legal process. This probability depends not only on the quality of the invention, but also on the characteristics of each particular competitor. Consequently, patents provide less chances in court against better infringers, reducing the protection.

Introducing patent enforcement in the decisions to innovate changes some of the usual policy recommendations. We show that in some circumstances providing more breadth can slow down not only the arrival of future innovations, but also reduce the incentives to patent. The reason is that the profits that the patentee obtains depend on both the production of the good and the revenues from licensing. To the extent that more protection diminishes the incentives to undertake future research, the revenues from licensing the patent could be reduced.

Finally, we study the effect of the legal environment on the decisions to innovate. We focus on two examples. In the first we analyze the case where a patent holder asks for a preliminary injunctive relief, in order to prevent other firms from producing while the legal process is resolved in court. We provide a numerical example in which firms benefit from it, but the effect on social welfare is ambiguous.

In the second application we analyze the effect of different ways to allocate litigation costs on the profits from settlement and the kind of licensing agreement offered. We concentrate on two common rules. In the English one, the loser pays all the litigation costs, while in the American rule each party bears its own costs. The results show that in the first case, competitors are less likely to appear, and there is less litigation. 
One system will be superior to the other depending on which effect is predominant.

The model is presented in Sections 2, 3 and 4. Section 5 compares the results with a setup without litigation. Section 6 considers some extensions and section 7 provides a numerical example. Section 8 concludes. All the results are proven in the Appendix.

\section{The Model}

Consider a market in which products are ordered in a quality ladder. Initially, there is a unique firm, the patentee (or patent holder), that holds a patent for a good of quality $v$, which is common knowledge to both consumers and other producers.

A second firm, denoted as the infringer, obtains an idea to improve the good by an amount $\Delta$. Although obtaining this idea is free, the firm cannot collect profits unless a quantity $c$ is invested to transform the idea into an operating invention. ${ }^{4}$ The size of the improvement $\Delta$ is private information that the infringer holds. The patentee knows only that $\Delta$ is drawn from a distribution $\Phi(\Delta)$ with density function $\phi(\Delta)>0$ in all the support.

There is a unique consumer with preferences of the form $u(v)=v-p$, where $v$ represents quality and $p$ is the price paid for the good. We denote the profits that firms obtain by $\pi$, with a subscript $p$ for the patentee and $i$ for the infringer. They sell at most one unit which is produced at a marginal cost of 0 . This implies that $\pi_{n}=p_{n}$ for $n=p, i$.

Firms are price competitors, and as a consequence if only the patentee produces, profits become $\pi_{p}^{M}(v)=v$, while if only the infringer does $\pi_{i}^{M}(v, \Delta)=v+\Delta$. Finally, if both firms compete duopoly profits are $\pi_{p}^{D}(v, \Delta)=0$ and $\pi_{i}^{D}(v, \Delta)=\Delta .^{5}$

\footnotetext{
${ }^{4}$ These assumptions, as well as the structure of the product market, are similar to those used by O'Donoghue, et al. (1998).

${ }^{5}$ The model can be easily reinterpreted as incremental cost reducing innovations.
} 


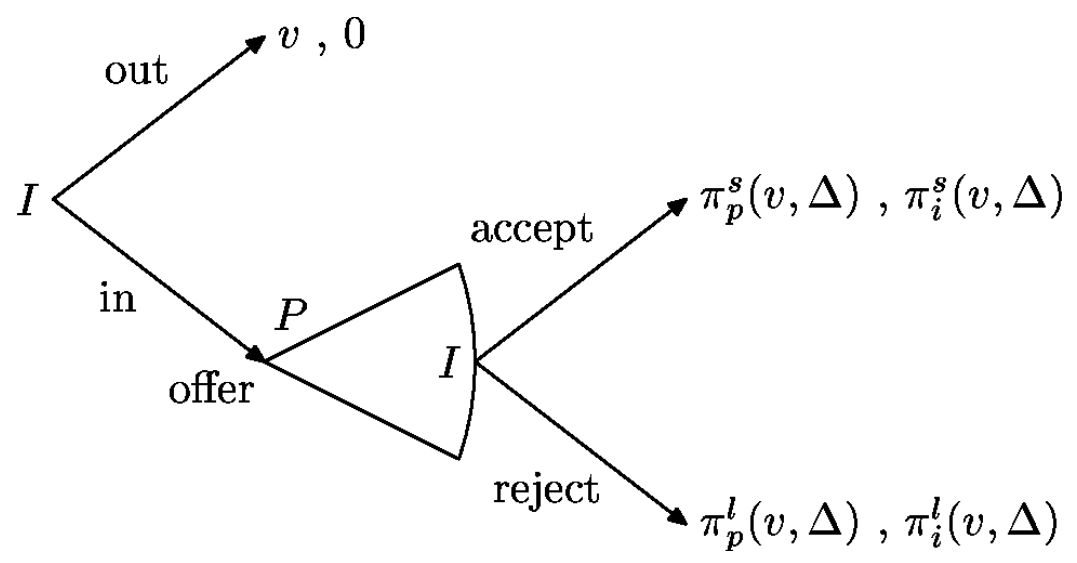

Figure 1: The Litigation Game.

The patent system is modelled in the following way: The patent is granted to the first inventor. Later, if the potential competitor produces an innovation, the patentee can try to reach a settlement or litigate the infringement. The result of the litigation process will depend on the difference, $\Delta$, between the quality of the new product and that of the patented one, and on how favorable to the patentee are the statutes and their interpretation by courts.

The structure and timing of the game are shown in Figure 1.

First, the infringer needs to decide whether or not to turn the idea into an invention by incurring the irreversible cost $c$. If there is no entry the patentee will be the only firm to produce, obtaining profits of $v$.

Upon infringer's entry, the patentee may try to negotiate a settlement with her. If the negotiation process is successful and the offer accepted, profits will be $\pi_{p}^{s}(v, \Delta)$ and $\pi_{i}^{s}(v, \Delta)$ for the patent holder and the infringer

In that case, the good is homogeneous, but the patentee has a production cost of $c_{p}$, while the infringer reduces it to $c_{i}=c_{p}-\Delta$. All the results of the paper follow under this specification. 
respectively. Otherwise, the patentee will sue the other firm arguing infringement. Courts will also assign the rights to produce while the process is resolved in court. The joint profits obtained given those rights will be denoted by the function $R(v, \Delta)$. This function is bounded above by assigning monopoly power to the second firm which would obtain $v+\Delta$ and below by not allowing any firm to produce, resulting in 0 profits. ${ }^{6}$ We assume that $R$ is weakly increasing in $\Delta$. The decisions of both firms can be described as strategies of a Bayesian Game.

The legal process will determine how the total revenue $R(v, \Delta)$ is allocated between the patentee and the infringer according to the functions $\pi_{p}^{l}(v, \Delta)$ and $\pi_{i}^{l}(v, \Delta)$. Of course, some legal costs $L>0$ will be incurred. Hence,

$$
R(v, \Delta)-L=\pi_{p}^{l}(v, \Delta)+\pi_{i}^{l}(v, \Delta) .
$$

In solving the game we focus on its sequential equilibria. Every infringer decides whether to enter or not and in the first case if the settlement offer made will be accepted. The patentee does not observe $\Delta$ when infringement of his patent occurs but he has some beliefs about the characteristics of the other firm, and according to them, he will make an offer. Conceivably the patentee could threaten to go to court every time infringement occurred in order to deter potential entrants. However, after infringement, he might have incentives to settle avoiding costly litigation, if for example, he believes that $\Delta$ is so high that his chances in court are small. Hence, we need to characterize when it will be in the interest of the patent holder to credibly litigate and what offer will be made.

The fact that $\Delta$ is private information restricts the kind of settlement schemes that the patentee might implement. In any event, if the com-

\footnotetext{
${ }^{6}$ In general courts allow both firms to produce while the process is resolved. This decision results in profits of $\Delta$ for the infringer and 0 for the patentee. In recent years a motion to stop the infringer from producing has become popular. It is referred as Preemptive Injunctive Relief and it allows the patentee to obtain profits of $v$. These two cases will be the focus in the remaining of the paper. However, other rules could be considered.
} 
petitor is allowed to use the invention, the patent holder will be better off by not producing, since competition lowers the profits of the licensee and consequently the value of a license. ${ }^{7}$

In such an environment the natural kind of contract has the following structure: the patentee allows the infringer to keep a share $\alpha$ of total profits and in exchange, the patentee receives a payment of $T$ and the remaining share of profits, $1-\alpha$. Therefore, given a standing patent of value $v$, if an infringer with quality $\Delta$ accepts a license $\{\alpha, T\}$ profits become,

$$
\pi_{i}^{s}(v, \Delta,\{\alpha, T\})=\alpha(v+\Delta)-T .
$$

We will call $\sigma_{i}$ the strategy played by the infringer. It consists of two elements: the decision to enter and the acceptance or rejection of the offer. An infringer will accept the settlement if $\pi_{i}^{s}(v, \Delta,\{\alpha, T\}) \geq \pi_{i}^{l}(v, \Delta)$. Otherwise, she will choose to fight the patentee in court. In a first stage, if the infringer expects to be offered a contract $\{\alpha, T\}$ upon entry, she will decide to pay the development cost $c$ if either the licensing agreement or the expected revenue from litigation are greater than $c$. In other words, if

$$
\max \left\{\pi_{i}^{s}(v, \Delta,\{\alpha, T\}), \pi_{i}^{l}(v, \Delta)\right\} \geq c .
$$

Although the patentee does not observe $\Delta$ at the time the licensing offer is made, he could do better in some cases than providing a unique license if instead he offered a menu of contracts $\{\alpha(\Delta), T(\Delta)\}$, each of them intended to a different type of infringer. Of course, infringers do not have any incentive to reveal the quality of their invention. Therefore, the menu must be designed in such a way that all infringers prefer to choose the licensing contract that is intended to them. In that case, the contract will be implementable.

\footnotetext{
${ }^{7}$ In this model monopoly profits do not cause any welfare loss. For this reason, collusive agreements will always be optimal from a social point of view, since they provide more incentives for research to be undertaken. See Green and Scotchmer (1995) for an extensive treatment of the relationship between antitrust policy and innovation.
} 
For now we will assume that $\pi_{i}^{l}(v, \Delta)$ has a slope greater than one with respect to $\Delta$, and we will later provide a setup that satisfies this constraint. Thus, profits from litigation grow faster than the ones from settlement (that grow at a rate $\alpha$ ) and so, there will be a threshold value $\Delta_{s}$ such that only those infringers with $\Delta \leq \Delta_{s}$ will accept the settlement, while the others will go to court. This threshold is defined by

$$
\pi_{i}^{l}\left(v, \Delta_{s}\right)=\alpha\left(\Delta_{s}\right)\left(v+\Delta_{s}\right)-T\left(\Delta_{s}\right)=\pi_{i}^{s}\left(v, \Delta_{s},\{\alpha, T\}\right)
$$

The next lemma, using standard Mechanism Design arguments, describes which are the conditions for a menu of contracts to be implementable:

Lemma 1 A mechanism $\{\alpha(\Delta), T(\Delta)\}$ is implementable if and only if $\alpha(\Delta)$ is non-decreasing in $\Delta$ and

$$
T(\Delta)=\alpha(\Delta)(v+\Delta)-\pi_{i}^{l}\left(v, \Delta_{s}\right)+\int_{\Delta}^{\Delta_{s}} \alpha(y) d y
$$

In as much as infringers with better inventions value their share of profits $\alpha$ relatively more than those with worse ideas, $\alpha(\Delta)$ must be increasing for a contract to be implementable. This also means that the contract associated with a higher $\Delta$ will also require a bigger payment $T$. In particular, equation (4) describes, for any $\alpha(\Delta)$ and $\Delta_{s}$ the payment schedule that guarantees that all infringers will be at least indifferent between declaring their type and misrepresenting it.

Despite the fact that the patentee does not know the quality of the infringer, he has some beliefs about it. It is easy to see that for any $0<\alpha \leq 1,{ }^{8}$ the profits accrued by an infringer according to (2) are strictly increasing in $\Delta$, meaning that if a certain competitor enters, all others with a higher quality will also be interested in entering. For this

\footnotetext{
${ }^{8}$ The case with $\alpha=0$ is special and analyzed in Appendix B. In particular, the lack of commitment to litigate from the patentee allows all infringers to enter regardless of their quality.
} 
reason, beliefs will take the form of a minimum size of competitor $\underline{\underline{ }}$ that the patentee expects to face. Conditional on that belief, the patentee will offer the contract that maximizes expected profits according to,

$$
\begin{aligned}
& W(v, L \mid \underline{\underline{\Theta}})=\max _{\alpha(\Delta), \Delta_{\mathrm{s}} \underline{\underline{\Theta}}} \mathrm{Z}_{\Delta_{\mathrm{s}}}[(1-\alpha(\Delta))(v+\Delta)+T(\Delta)] \frac{\phi(\Delta)}{1-\Phi \underline{\underline{\mathrm{Q}}}} d \Delta+ \\
& +{ }_{\Delta_{\mathrm{s}}}^{\mathrm{Z}} \mathrm{h}(v, \Delta)-L-\pi_{i}^{l}(v, \Delta)^{\mathrm{i}} \frac{\phi(\Delta)}{1-\Phi \underline{\underline{\mathrm{g}}}} d \Delta \text {, } \\
& \text { s.t. } \alpha(\Delta) \geq \alpha\left(\Delta^{9}\right) \text { if } \Delta \geq \Delta^{0} \text { and (4). }
\end{aligned}
$$

That is, for a given belief $\underline{\underline{E}}$, the patentee only needs to choose the profile $\alpha(\Delta)$ and the minimum size of the litigated invention $\Delta_{s}$. Profits will correspond to the royalty rate $(1-\alpha(\Delta))$, the fee paid on those cases settled, and the expected revenue from litigation on the rest. The constraints imposed guarantee according to Lemma 1, that the contract is implementable.

The first result shows that the patentee will never offer more than one contract and it is characterized by a unique licensing fee, while royalties will never be used.

P roposition 2 For any belief $\underline{\underline{Q}}$, the optimal licensing settlement consists of $\alpha(\Delta)=1$ for all $\Delta$. Moreover, $T$ is weakly decreasing in $\underline{\underline{\theta}}$.

The intuition of why $\alpha(\Delta)=1$ is optimal can be illustrated as follows. Royalties are relatively more expensive for good infringers; fixed license fees for the poor ones. At the margin of litigation, it is the best infringer that requires the largest incentive to settle out of court; the poor infringers are inframarginal and will settle with a smaller incentive. Suppose that the patent holder wants the minimum size of a litigated innovation to equal $\Delta_{s}$. To implement the same threshold with a $\alpha<1$ the patentee needs to charge a lower fee $T$ since he is keeping a higher share of profits. Therefore, the patentee is also reducing the fee that he receives from all the other infringers by a bigger amount than the increase in royalty revenues that he receives. 
Given a licensing fee $T$, the strategy used by an infringer, $\sigma_{i}$, can be characterized in the following way. We know that only those infringers with $\Delta>\Delta_{s}$ will go to court. Moreover, there will be a threshold $\underline{\Delta}$ so that firms with a quality below it will not enter. From equation (2), $\underline{\Delta}$ is obtained as

$$
\Delta+v-T-c=0 .
$$

Infringers with $\Delta \in\left[\underline{\Delta}, \Delta_{s}\right]$ will accept the settlement offer. Therefore, $\sigma_{i}$ can be defined as,

$$
\sigma_{i}= \begin{cases}(\text { out, accept) } & \text { if } \Delta \leq \Delta \\ (\text { in, accept }) & \text { if } \Delta \in\left[\underline{\Delta}, \Delta_{s}\right] \\ \text { (in, reject) } & \text { if } \Delta>\Delta_{s} .\end{cases}
$$

Of course, for a licensing contract $T$ to be part of a Sequential Equilibrium, the patentee must hold beliefs consistent with the strategy played by the infringer. The next definition states the corresponding requirements:

Definition 1 A Pure Strategy Sequential Equilibrium of the Litigation Game given a patent holder with invention $v$ will be a strategy profile $\left(T^{*}, \sigma_{i}^{*}\right)$ supported by beliefs $\widetilde{\Delta}$ such that,

(i) $T^{*}$ maximizes expected profits for the patent holder in (5) given beliefs $\widetilde{\Delta}$;

(ii) $\sigma_{i}^{*}(\Delta)$ maximizes for all $\Delta$ expected profits for the infringer given $T^{*} ;$ and

(iii) The belief $\widetilde{\Delta}$ is consistent with the strategy played by the infringer. That is, $\widetilde{\Delta}=v-T^{*}-c$.

The next proposition shows that this game has a unique sequential equilibrium.

Proposition 3 The Litigation game has a unique Sequential Equilibrium in pure strategies. 


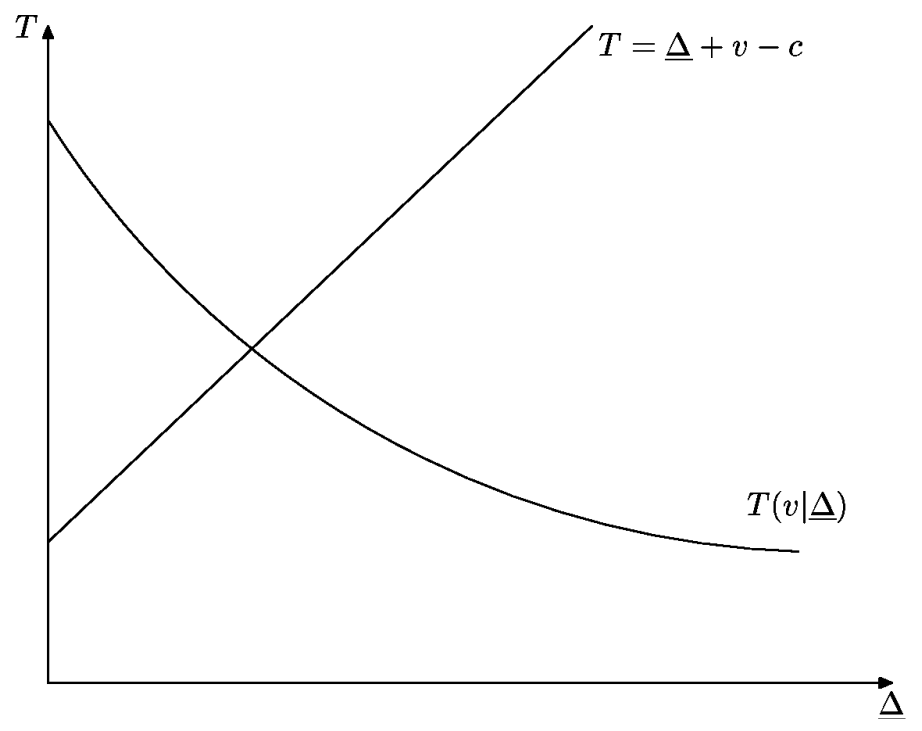

Figure 2: The conditions that define the Sequential Equilibrium of the game.

The characterization of this unique sequential equilibrium is fairly simple. From the problem stated in (5) we obtain for any belief $\widetilde{\Delta}$ the optimal licensing fee $T(v, L \mid \underline{\underline{\Delta}})$. On the other hand, equation (6) describes how the decision of entry by the infringer is determined. Using Definition 1 the sequential equilibrium can be obtained as the $T^{*}$ and $\underline{\Delta}^{*}$ that satisfy the conditions,

$$
\begin{aligned}
& T^{*}=T\left(v, L \mid \underline{\Delta}^{*}\right), \\
& \underline{\Delta}^{*}=T^{*}-v+c .
\end{aligned}
$$

From Proposition 2, T is weakly decreasing in $\widetilde{\Delta}$ and as a result there can be at most a pair $\left(T^{*}, \underline{\Delta}^{*}\right)$ satisfying these two constraints. Of course, it could be the case that $T(v, L \mid 0)<v-c$ so that these curves do not cross. In this case, it is easy to verify that $\underline{\Delta}^{*}=0$ and $T=v-c$ constitutes a 
Sequential Equilibrium. ${ }^{9}$

In the next sections we impose more structure on the model, which allow us to analyze different legal environments and their effect on growth, welfare and the incentives to innovate. We use as a benchmark model a representation of the system prevalent in the United States.

\section{The Benchmark Case}

We now give specific assumptions about the legal structure and the litigation technology available. In particular, we provide structure on the function $R(v, \Delta)$, that regulates the revenue that inventors receive while the legal process is resolved in court, as well as the way in which these profits are distributed between the patentee and the infringer.

In the United States courts tend to allow firms to produce until a verdict on infringement is achieved. Therefore, both firms compete in the production of the good. The patentee and the infringer obtain profits of 0 and $\Delta$ respectively, and so $R(v, \Delta)=\Delta$.

During the legal process, courts observe a signal of the true quality of the alternative invention. This observation allows them to decide with a certain probability $q$ that the new invention is not infringing the original patent. This probability is assumed to depend on the quality of the alternative invention, $\Delta$ and a parameter $b$ related to how favorable to the patentee are courts in their rulings. Therefore, $q(\Delta, b)$ is increasing in $\Delta$ and decreasing in $b$. Most important, the effect of protection on entry will depend on the sign of $\frac{\partial^{2} q}{\partial \Delta \partial b}$. We next provide two examples of a function $q$.

Example 1 (See Figure 3) Suppose that courts observe a signal of $\Delta$, denoted as $\widehat{\Delta}$. We assume that $\widehat{\Delta}$ is uniformly distributed between $\Delta(1-z)$

\footnotetext{
${ }^{9}$ The existence of a pure strategy equilibrium depends on the assumption on the support of $\Delta$. Nevertheless, even if this condition is not met, an equilibrium will in general exist, although in mixed strategies.
} 
and $\Delta(1+z)$ where $z \in[0,1]$. The parameter $z$ reflects the precision of the legal technology. When an invention represents a small improvement $\Delta$, it is fairly simple to assert that the invention is infringing on the patent. However, as the invention differs more and more from the previous state of the art, it becomes more difficult for courts to evaluate its features. This ambiguity depends on other factors, such as previous rulings in a particular sector or the speed of innovation.

We interpret $b$ as a threshold value: only if courts observe $\widehat{\Delta}>b$ they conclude that the new invention was not infringing the original patent. ${ }^{10}$ It is easy to see that this will happen with probability

$$
q(\Delta, b, z)= \begin{cases}0 & \text { if } \Delta<\frac{b}{1+z}, \\ \frac{\Delta(1+z)-b}{2 \Delta z} & \text { if } \Delta \in\left[\frac{b}{1+z}, \frac{b}{1-z}\right], \\ 1 & \text { if } \Delta>\frac{b}{1-z} .\end{cases}
$$

We can verify that $q(\Delta, b, z)$ is increasing in $\Delta$ and decreasing in $b$ and that $\frac{\partial^{2} q}{\partial \Delta \partial b}=0$ where differentiable.

In general, we would expect the function $q(\Delta, b)$ to be s-shaped with respect to $\Delta$, with $\lim _{b \rightarrow \infty} q(\Delta, b)=0$ and $\lim _{\Delta \rightarrow \infty} q(\Delta, b)=1$. In this case, for low values of $\Delta \frac{\partial^{2} q}{\partial \Delta \partial b}<0$, turning positive as $\Delta$ increases.

Example 2 An example of this specification is the following logistic function $^{11}$ :

$$
q(\Delta, b, z)=\frac{1}{1+\exp (z-\Delta+b)}
$$

One possible interpretation of this probability is a threshold rule. That is, when $\Delta=b+z$ the infringer wins with probability $\frac{1}{2}$. In this case, $\frac{\partial^{2} q}{\partial \Delta \partial b}>0$ if and only if $\Delta>b+z$. Notice that $\lim _{\Delta \rightarrow \infty} q(\Delta, b, z)=1$.

\footnotetext{
${ }^{10}$ See Chang (1995) for a discussion on the determinants of court rulings. In particular, he provides arguments for this kind of threshold rule to be optimal.

${ }^{11}$ I thank Michael Manove for this example.
} 

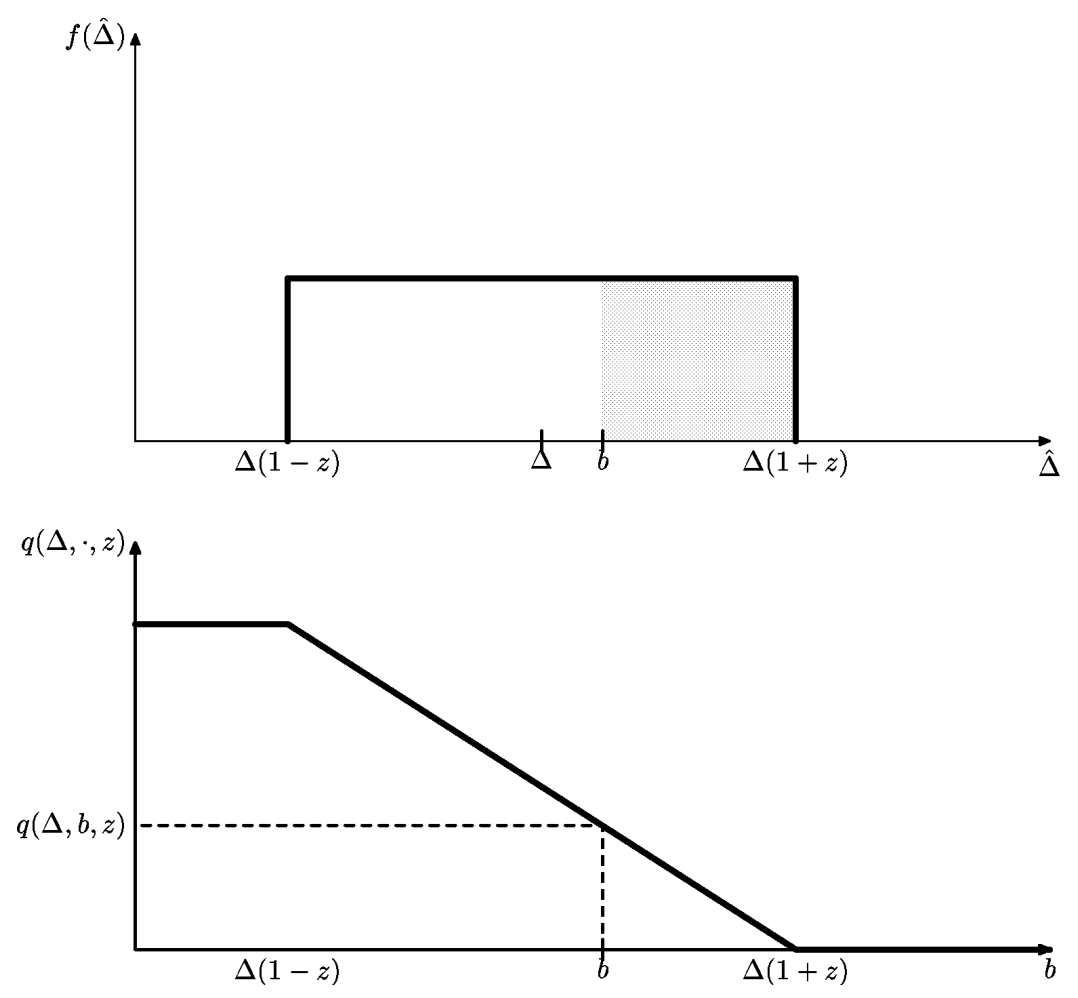

Figure 3: A Litigation Technology.

The Litigation Technology will also involve some legal expenses. These litigation costs are denoted as $L_{p}$ and $L_{i}$ for the patentee and the infringer respectively. Court rulings might also decide on how these costs are distributed, imposing compensations from the loser to the winner for the legal costs incurred. This case is studied later in the paper.

If the infringer loses in the procedure, which occurs with probability $1-q(\Delta, b)$, she will have to compensate the patentee for the foregone profits, $\pi_{p}^{M}(v)=v$. Otherwise, she can keep the earnings from production. In any case, litigation costs $L_{i}$ are incurred. Therefore, the expected return 
for the infringer when going to court is,

$$
\pi_{i}^{l}\left(\Delta, b, L_{i}\right)=\Delta-(1-q(\Delta, b)) v-L_{i}
$$

These profits are increasing in $\Delta$ and decreasing in $b$. Moreover, $\frac{\partial \pi_{i}^{l}}{\partial \Delta}>$ 1 , satisfying the assumptions placed in the previous section.

In the legal process, the patentee will succeed with probability 1 $q(\Delta, b)$ resulting in a compensation for the lost profits from production, $v$, net of litigation costs, $L_{p}$, or

$$
\pi_{p}^{l}\left(\Delta, v, L_{p}\right)=(1-q(\Delta, b)) v-L_{p}
$$

The profit function corresponding to equation (5) becomes in this case

$$
\begin{aligned}
W\left(v, b, L_{i}, L_{p} \mid \underline{\widetilde{\Delta}}\right)= & \max _{\Delta_{s}} \int_{\Delta_{s}}\left[(1-q(\Delta, b)) v-L_{p}\right] \frac{\phi(\Delta)}{1-\Phi(\underline{\underline{\Delta}})} d \Delta+ \\
& +\left[\frac{\Phi\left(\Delta_{s}\right)-\Phi(\underline{\widetilde{\Delta}})}{1-\Phi(\underline{\widetilde{\Delta}})}\right] T \\
& \text { s.t. } T=\left(2-q\left(\Delta_{s}, b\right)\right) v+L_{i} .
\end{aligned}
$$

The next result explains in this case how the licensing offer depends on the parameters of the model and the legal environment.

Lemma 4 For any belief $\widetilde{\widetilde{\Delta}}$, the optimal licensing agreement consists of

(i) $T\left(v, b, L_{i}, L_{p}, \widetilde{\Delta}\right)$ increasing in $v$ and decreasing in $L_{p}$ and $\widetilde{\widetilde{\Delta}}$,

(ii) $\Delta_{s}\left(v, b, L_{i}, L_{p}, \widetilde{\Delta}\right)$ increasing in $L_{p}, L_{i}$ and $\widetilde{\Delta}$ and decreasing in $v$ and

(iii) $W\left(v, b, L_{i}, L_{p} \mid \underline{\widetilde{\Delta}}\right)$ strictly increasing in $v, b$ and $L_{i}$ and decreasing in $L_{p}$.

Moreover, if $\frac{\partial^{2} q}{\partial \Delta \partial b} \geq 0, T$ is increasing in $b$ and $\Delta_{s}$ is decreasing in $b$. 
The effect of most of the parameters is as expected. The amount that the patentee demands for a license is increasing in all the characteristics that streghten his position. More protection or lower legal costs increase the interest in going to court. Obviously they also make litigation costlier to the infringer, increasing her willingness to pay to avoid it. Additionally, if the patentee believes that the conditional distribution of infringers is better $-\widetilde{\widetilde{\Delta}}$ increases - , he will decide to litigate less often, resulting in a lower price for the license.

We also obtain the compelling result that the probability of settlement is increasing in the legal costs incurred by any of the parties, although for different reasons. An increase in $L_{p}$ gives more incentives to the patent holder to avoid litigation, while higher $L_{i}$ allows the patentee to increase the licensing fee $T$ and still induce a similar amount of litigation.

The previous lemma also characterizes the expected profits for the patentee given any belief $\underline{\underline{\Delta}}$, represented by $W\left(v, b, L_{i}, L_{p} \mid \widetilde{\underline{\Delta}}\right)$. The value of holding a patent increases when $L_{i}$ rises. The reason is that an increase in the litigation cost faced by the infringer weakens her position. That is, the revenue that infringers expect to obtain from litigation decreases, and hence they are interested to settle for less. Similarly, it is natural to think that an increase in $L_{p}$ leads to a decrease in $W$.

Finally, for a fixed distribution of infringers, there is no reason to believe that the patentee will be worse off when the protection granted increases. However, as we will see in the next sections, it does not mean that ex-ante profits increase when more protection is granted.

The results in Lemma 4 do not take into account that changes in the legal structure can affect the equilibrium entering decision of infringers. It is expected that a more pro-patent legislation might discourage competitors to invest.

However, once we consider the effect that changes in the legal technology have in the size of the smallest entrant, in the sequential equilibrium described in Definition 1, the result changes, as we see in the next proposition. These effects can be explained as shifts in the curves displayed in 
Figure 2.

Proposition 5 In the unique pure strategy Sequential Equilibrium of the Litigation game,

(i) Litigation is decreasing in c,

(ii) Entry is decreasing in $v$ and $c$ and increasing in $L_{p}$ and

(iii) $T^{*}$ is increasing in $v$ and decreasing in $L_{p}$ and $c$.

If $\frac{\partial^{2} q}{\partial \Delta \partial b} \geq 0$ entry is decreasing in $b$ and $T$ increasing in $b$.

The effect of $b$ on entry and the licensing fee when $\frac{\partial^{2} q}{\partial \Delta \partial b} \geq 0$ is not surprising. As $b$ raises, the patentee sees his position reinforced, willing to demand more for a license. This fact obviously dissuades some potential entrants. However, potential hold-ups may occur. If $\frac{\partial^{2} q}{\partial \Delta \partial b}$ is sufficiently negative, $\Delta_{s}$ is increasing in $b$ and the patentee might not be able to commit to a higher licensing fee, resulting in more entry, since

$$
\frac{\partial T}{\partial b}=-\left(\frac{\partial q}{\partial b}+\frac{\partial q}{\partial \Delta_{s}} \frac{\partial \Delta_{s}}{\partial b}\right) v
$$

In recent empirical studies, some attention has been devoted to the relationship between breadth of a patent and the probability of being litigated. While most of the papers, such as Lerner(1994) suggest that broader patents are litigated more often, some other evidence presented by Lanjouw and Schankerman (1997) predicts the opposite relationship.

This model stresses the forces that might make each of the results prevalent. When $\frac{\partial^{2} q}{\partial \Delta \partial b} \geq 0$, an increase in the protection has two effects. The direct effect implies a decrease in settlement, since the patentee expects to obtain higher profits by going to court, in the direction outlined by Lerner (1994). The second is a selection effect. The patentee demands more for a license, inducing less infringers to enter. This fact improves the distribution of competitors that the patentee faces, making settlement more appealing. Numerical examples indicate that the direct effect usually 
predominates for low values of $b$, while the selection effect is increasingly important as the protection increases.

The previous lemma also shows that increases in the protection are to some extent equivalent to decreases in the legal costs that the patentee incurs, $L_{p}$. In other words, both are considered barriers to entry to future competitors. The quality of the patented invention has a similar effect. A higher $v$ implies that the infringer has to pay a higher compensation to the patent holder if she loses in court.

Empirical evidence supports these results. Lerner (1995) shows that firms, especially small ones, tend to direct their research or patenting activities away from sectors where big firms are established. These firms are likely to have smaller legal costs and an important number of patents.

Legal costs have also an ambiguous effect on the amount of litigation we expect to see. Higher costs make litigation less appealing, and a lower licensing fee is expected in order to avoid it. However, as in the case of $b$, a lower licensing fee induces more entry, reducing the incentives to offer a settlement. The resulting effect on litigation will depend on which force prevails.

Finally, technological parameters do not affect the decisions to litigate, and therefore, the selection effect is always predominant. A higher cost of invention $c$ induces less and better firms to enter, decreasing the interest of the patentee in litigating.

\section{The Incentives to Innovate}

In the previous sections we have analyzed which are the effects of the legal environment in the incentives for other firms to engage in $R \& D$ when there is an innovator already in the market. However, the legal structure has also an impact on the incentives for inventions to be patented. One might expect that more favorable courts or lower litigation costs would increase the profits from innovation. As we show in this section, this will not always be the case. 
The reason is that firms obtain profits not only from their inventions but also from the future stream of profits that posterior uses of their ideas generate, usually through licensing. Therefore, two forces must be taken into account. A more favorable environment allows the patentee to accrue profits for a longer period of time. However, this same change alters the incentives for other firms to produce, affecting the licensing benefits that the patentee can collect due to infringement.

We assume that all innovators face the same technology. Therefore, the patentee incurs in a constant research cost of $c$ to implement the idea $v$. Moreover, a patent needs to be purchased at a price $f$. Ex-ante profits from patenting will be denoted as $W_{0}$ and obtained as

$$
W_{0}\left(v, b, L_{i}, L_{p}\right)=\Phi\left(\underline{\Delta}^{*}\right) v+\left(1-\Phi\left(\underline{\Delta}^{*}\right)\right) W\left(v, b, L_{i}, L_{p} \mid \underline{\Delta}^{*}\right)-c-f
$$

where $\underline{\Delta}^{*}$ is the infringer indifferent between entering and staying out, derived from the sequential equilibrium of the game.

The different forces described in the previous section make difficult to obtain clear predictions in most of the cases. However, Lemma 4 and Proposition 5, allow us to derive the following result:

Lemma 6 If $\frac{\partial^{2} q}{\partial \Delta \partial b}>0$, there exists a $v^{*}$ such that for all $v<v^{*}, W_{0}$ is strictly decreasing in $b$.

Changes in $b$ affect the profits that an inventor might obtain in two different ways. The patentee is better off because his expected profits in court for any threshold value $\Delta$ rise as stated in Lemma 4. At the same time, the patentee will set a higher licensing fee $T$, discouraging some infringers to appear. To the extent that the patentee derives an important share of profits from licensing to future innovators, the second effect will be predominant. This is the case for example when $v$ is small, which can be easily identified with those inventions that have a lower value by themselves compared to the future stream of innovations they generate. In this case, lower protection is preferred, because it allows to 
obtain higher licensing profits. Our results differ from previous findings in the literature. For example, Chang (1995) recommends in a similar model without private information on the value of infringing innovations to award more protection to firms with low $v$. As our model suggests, such a result might not be robust to this assumption.

In general, numerical results show that for any value of $v, W_{0}$ is not monotonic in $b$, and firms prefer to have either very small or infinite protection to any intermediate situation. In some cases infinite protection might be desirable, mainly when $L_{p}$ is high, and the patentee benefits more from reducing the probability of litigation than obtaining a higher license $T$.

From equation (12) it can be verified that profits are increasing in the quality of the invention, although at a decreasing rate. The reason is similar to the effect of $b$. The higher is $v$, the less competition is the patentee likely to face, leading to a lower licensing revenue.

\section{The Importance of Litigation}

The existence of litigation changes the incentives for firms to invent and patent, and also importantly, for new competitors to appear. There are two reasons for litigation to arise in this model. First, the fact that protection is not absolute, and instead, it depends on how different is the new invention from the already patented one. The second reason is the private information that the infringer holds about the quality of her invention. Without any of these features intellectual property rights could be perfectly enforced. As we will see, litigation helps the patentee to commit in the negotiation against future competitors. Otherwise the patentee has incentives to renege from any settlement made to the infringer, eroding the reasons for entry to occur.

We now turn to the study of the effects of each of our assumptions. Some earlier papers argued that in order to provide incentives for first generation innovators to appear, the patentee should internalize all the surplus 
that his invention generates. ${ }^{12}$ Hence, let's assume that the patentee is entitled to infinite breadth. Obviously, litigation in this case becomes redundant, and this means that a competitor will not be allowed to produce unless she reaches an agreement with the current patent holder.

As before, the quality of the inventions is $v$ for the patentee and $\Delta$ for the infringer, once the invention is completed at a cost $c$. The patentee offers a menu of contracts $\{\alpha, T\}$ consisting of a share that the infringer can keep of total profits, $\alpha$, and a fee $T$ to be paid. If the offer is accepted, profits for the infringer are

$$
\pi_{i}^{s}(\Delta, b,\{\alpha, T\})=\alpha(v+\Delta)-T-c,
$$

and $-c$ if it is rejected.

The patentee holds a belief $\widetilde{\Delta}$ about the worse infringer entering and according to it the settlement offer will be made. Notice that for any $\alpha>0$ and $T$, the most interested infringers in settling are the best ones. This feature constitutes an important difference with the case in which litigation is used, since there the best infringers were the ones rejecting the offer.

The kind of settlement that maximizes profits for the patentee in this case is fairly clear. It is enough to ask for a royalty corresponding to all the profits that the infringer can make and no fee, $\alpha=0$ and $T=0$. Because the cost $c$ is sunk after entry the infringer will always be indifferent between accepting or not and make losses of $c$. As a result, no firm will ever infringe the patent. This is an extreme form of the holdup problem.

This result is the opposite to the one obtained before, and corresponds to the patentee buying out the competitor. Why is it the case? When litigation is a threat the patentee wants to settle with those infringers that have more chances to win in court, i.e. the ones with the highest quality.

\footnotetext{
${ }^{12}$ Of course, increasing protection reduces the incentives for future research to arrive. See O'Donoghue, Scotchmer and Thisse (1998) and Llobet, Hopenhayn and Mitchell (2000) for a general treatment of this issue.
} 
The cheapest way to do it is by allowing them to obtain bigger profits. This is achieved when they keep all the return from their production.

The second reason for litigation to arise is the existence of private information. Suppose that, as in Chang (1995), $\Delta$ is public information, observable to the patentee and courts. For this reason, $b$ can be interpreted as a threshold value - as in Example 1 -. That is, legislation sets a threshold $b$ on the minimum size of the new invention that does not infringe the patent. It is easy to see that two cases might arise. If $b<c$, breadth becomes irrelevant. That is, the infringer will only enter if $\Delta$ is bigger than $c$, so that it makes positive profits. If $b>c$, all inventors with $b \geq \Delta \geq c$, will not enter because the patentee cannot commit to offer a license even though it is mutually beneficial. Notice that the patentee will earn $v$ when the competitor does not produce. However, if $\Delta>b$, he can try to license his invention to the competitor, and earn at most $v$. Hence, profits become,

$$
W_{0}(v, b)=v \Phi(\max \{b, c\})+(1-\Phi(\max \{b, c\})) T
$$

for $T \leq v$. It is obvious that in this case ex-ante profits for the patentee are weakly increasing in the protection offered. This result differs from the case with private information as discussed in the previous section.

To summarize, we observe that litigation has several important implications. It affects the optimal licensing agreement that the patentee will offer, and by providing more incentives for future innovation to arise, it might increase growth. It also affect the recommendations that we can make regarding the use of breadth to provide incentives to innovate.

\section{Changes in the Legal Environment}

The framework developed in the previous sections can be used to derive policy implications. We focus on two of them: the effect of Preliminary Injunctive Relief and the way in which litigation costs are allocated. 


\subsection{Preliminary Injunctive Relief}

One of the assumptions that we have maintained throughout the paper is that while the legal procedure is resolved, both firms compete in the production of the good. However, in recent years, as it has been documented by Lanjouw and Lerner (1997) a legal motion known as Preliminary Injunctive Relief (PIR), has become popular. ${ }^{13}$ This motion allows the patentee to stop the other firm from producing until a verdict is reached. While the profits that the patentee gets in this case are higher, it also implies that the infringer must be compensated if courts rule against him. Therefore the final effect is a priori ambiguous, and it might depend on the distribution of $\Delta$. In this section we study the equilibrium of the game when this motion is filed and we discuss which patentees benefit from it.

Under the PIR, the patentee will still be the only producer, obtaining profits of $v$. Therefore $R(v, \Delta)=v$. After production the legal process will take place and if the infringer wins, which occurs with probability $q(\Delta, b)$, he will be compensated for the lost profits. Hence,

$$
\pi_{p}^{l}\left(\Delta, v, b, L_{p}\right)=v-q(\Delta, b) \Delta-L_{p}
$$

As before we study the optimal licensing agreement that the patentee can offer. Using Proposition 2 we know that from all the menus of royalties and fees $\{\alpha, T\}$ it is optimal to just use a licensing fee $T .{ }^{14}$ This fee determines which infringers will go to court and those that will settle.

\footnotetext{
${ }^{13} \mathrm{~A}$ recent example illustrates this practice:

On July 30, 1999 Marimba Inc. filed an action for infringement of patent 5,919,247 against Novadigm. In its complaint Marimba seeked monetary damages, as well as an injunction to prevent Novadigm from making, using or selling infringing software products.

${ }^{14}$ We need to assume that $q(\Delta, b) \Delta$ grows at a rate bigger than one. The function described in Example 1 satisfies this condition.
} 
The threshold value, denoted $\Delta_{s}$ as before, is obtained from

$$
\pi_{i}^{l}\left(\Delta_{s}, v, b, L_{i}\right)=q\left(\Delta_{s}, b\right) \Delta_{s}-L_{i}=v+\Delta_{s}-T=\pi_{i}^{s}\left(\Delta_{s}, v, T\right),
$$

or,

$$
T=\left(1-q\left(\Delta_{s}, b\right)\right) \Delta_{s}+v+L_{i}
$$

It is easy to see that again, only those $\Delta>\Delta_{s}$ will prefer litigation to settlement. Profits correspond to $\pi_{p}^{l}\left(\Delta, v, b, L_{p}\right)$ if the infringer does not accept the settlement, and to the licensing fee $T$ otherwise. That is,

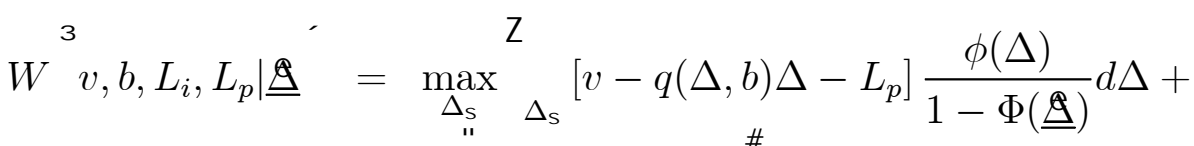

$$
\begin{aligned}
& +\frac{\Phi\left(\Delta_{s}\right)-\Phi(\underline{\underline{\Phi}})}{1-\Phi(\underline{\underline{\Phi}})} T \text {, } \\
& \text { s.t. (13). }
\end{aligned}
$$

The comparative statics in the Sequential Equilibrium of the game stated in Definition 1 are also very similar to the case without PIR. However, the effect of $v$ on the number of cases litigated is well defined.

Proposition 7 In the unique pure strategy Sequential Equilibrium of the Litigation game,

(i) Litigation is decreasing in $c$ and independent of $v$,

(ii) Entry is decreasing in $c$, increasing in $L_{p}$ and independent of $v$,

(iii) $T^{*}$ is increasing in $v$ and $b$ and decreasing in $c$ and $L_{p}$.

If $\frac{\partial^{2} q}{\partial \Delta \partial b} \geq 0, T^{*}$ is increasing in $b$.

When a PIR is requested, entry and litigation do not depend on $v$. This is an important difference with respect to the original case, because here better inventors do not deter more entry. To see it, notice that the 
profits that the infringer expects to obtain if she accepts the settlement are

$$
\pi_{i}^{s}\left(\Delta, b, T^{*}\right)=\Delta-\left(1-q\left(\Delta_{s}^{*}, b\right)\right) \Delta_{s}^{*}-L_{i}-c,
$$

independent of $v$. Obviously, this feature makes the optimal transfer $T^{*}$, according to equation (13), linear in $v$.

If we define the ex-ante profits that the patentee obtains as in Section 4 ,

$$
W_{0}\left(v, b, L_{i}, L_{p}\right)=\Phi\left(\underline{\Delta}^{*}\right) v+\left(1-\Phi\left(\underline{\Delta}^{*}\right)\right) W\left(v, b, L_{i}, L_{p} \mid \underline{\Delta}^{*}\right)-c-f
$$

the linearity of $T$ in $v$ and the fact that neither $\underline{\Delta}^{*}$ nor $\Delta_{s}$ are affected by $v$ are enough to show that $W_{0}$ is linear in $v$. That is,

$$
W_{0}\left(v, b, L_{i}, L_{p}\right)=v+W_{0}\left(0, b, L_{i}, L_{p}\right) .
$$

When comparing this case with the situation in which PIR is not considered, the results are considerably different. Here the profits that firms obtain increase linearly in $v$. This result means that the capacity that the patentee has to capture profits from future innovation is independent of the quality of the original invention as opposed to the case where PIR is not available. There, innovators with small improvements could capture a higher share of future research, by inducing more entry and obtaining the corresponding licensing fees.

A numerical example is provided later in the paper where the effect of PIR on innovation and social welfare is computed.

\subsection{The Allocation of Litigation Costs}

The model explicitly considers the litigation costs that each of the parties bears. This feature makes it especially suited to study how the decisions of the participant firms change when these costs vary, or when we compare different legal environments.

Two particular ways of allocating legal costs are of interest due to their empirical relevance. While with the American rule each party generally 
pays its own costs of going to trial, with the English one the loser pays all the costs. Because the incentives to innovate are different in each of the cases, the optimal patent will most likely depend on the system used.

There is an extensive literature on the effect of litigation costs in the cases that are finally brought to trial. Some recent examples include Bebchuk and Chang (1994) and Polinsky and Rubinfeld (1996). Their results show that none of the rules commonly considered is optimal. In particular, the American rule discourages some meritorious suits from being brought to trial while the English one induces some frivolous cases.

These papers usually consider general setups, without allowing for pretrial negotiation. The case of patent litigation has unique features, and changes in the legal institutions usually modify the firms' investment decisions. In this case they are mainly two, if an idea will be produced and what settlement offer will be made.

This section is closer in spirit to Meurer(1989), and especially to Reinganum and Wilde (1986). In the last they are interested in obtaining mechanisms that screen among different classes of plaintiffs. However, it differs from this model in the fact that the offer is made by the informed party leading them to focus on conditions for a separating (or semi-pooling) equilibrium to exist.

For simplicity, we study the case where $L_{i}=L_{p}=L$. The results do not depend on this assumption as long as the difference in costs is not substantial. The profits that the infringer and the patentee expect to obtain from litigation will be affected by the distribution of the cost between the winner and the loser. In particular, under the English rule, the infringer expects to pay all legal costs only when losing, which occurs with probability $(1-q(\Delta, b))$. Thus, profits become,

$$
\pi_{i}^{l}(\Delta, b, L)=\Delta-(1-q(\Delta, b)) v-(1-q(\Delta, b)) 2 L-c,
$$

and for the patent holder they are,

$$
\pi_{p}^{l}(\Delta, b, L)=(1-q(\Delta, b))(v+2 L)
$$


We focus on the optimal licensing mechanism, obtained as a unique licensing fee. It is easy to argue that $q\left(\Delta_{s}, b\right) \leq \frac{1}{2}$ is the most likely case. The effects of changing from one rule to the other are stated in the next proposition. ${ }^{15}$

Proposition 8 There exists a $q<\frac{1}{2}$ such that in the Sequential Equilibrium of the Litigation game, if $q\left(\Delta_{s}, b\right) \leq q$, moving from the American to the English rule results in higher licensing fees and less entry and litigation.

Therefore, switching to the English rule results in higher expected litigation costs for all the infringers that were settled before - those $\Delta<$ $\Delta_{s}$ - and the patentee can afford to increase $T$ and still keep the same level of settlement even for some $q<\frac{1}{2}$. The force driving the result is that for a constant $\underline{\Delta}$, the threshold value $\Delta_{s}$ does not depend on who pays the litigation costs but rather on its total value. Given the higher fees, less infringers will decide to enter. Because $\Delta$ raises, the patentee will be more interested in reaching a settlement, and therefore $\Delta_{s}$ will increase.

This result differs from the usual consequences obtained in the literature. The reason is that we allow for the possibility of licensing between the patentee and the competitor after entry.

The welfare consequences of both allocation rules are ambiguous. One of the implications of the model is that litigation should be more common in the U.S., together with a bigger speed of innovation. This means that the English rule seems better suited for innovations that have a high value compared with the future licensing fees they can obtain, while the American rule provides a better setting for small but fertile inventions to appear. Of course, this result depends on the assumption that there is enough protection, as stated in the proposition. Nevertheless, empirical evidence seems to indicate that the probability of winning in court of all the infringers that settle is relatively small.

\footnotetext{
${ }^{15}$ The same result can be obtained if, along the lines of the previous section, we assume that the patentee asks for a PIR.
} 


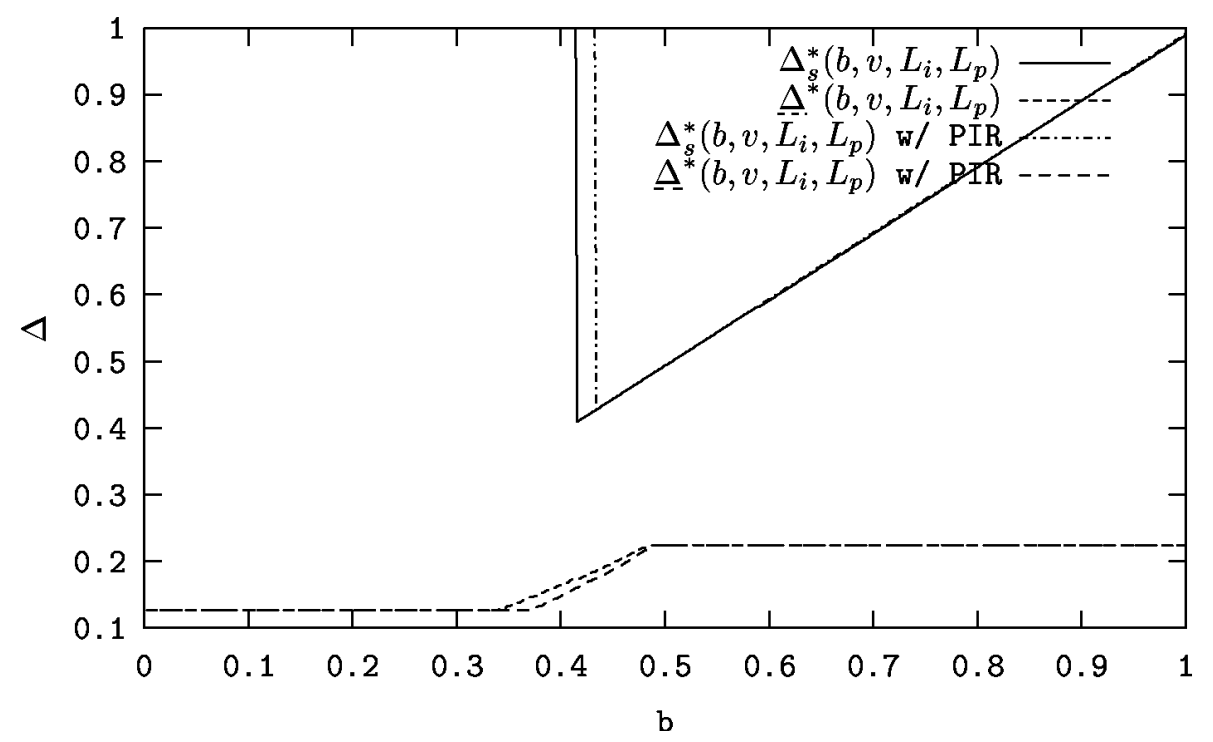

Figure 4: Entry, Settlement and Litigation when $v=1$ with and without PIR.

\section{A Numerical Example}

Here we show a numerical example that illustrates some of the results and intuitions outlined in the rest of the paper.

We assume that $\Phi$ is a Pareto-Levy distribution with parameter $\gamma=$ 0.5 and a minimum size of idea of 1 . That is, $\Phi(\Delta)=1-\Delta^{-0.5}$. The cost of innovation is normalized to 1 , and the litigation costs are $L_{i}=L_{p}=0.25$. The probability that courts rule in favor of the patent holder is as described in Example 2, with $z=2$.

In Figure 4 we simulate the range of inventions that are litigated and settled for different values of $b$ when $v=1$. In the benchmark case, as explained in Proposition 5, while the amount of entry decreases monotonically when $b$ increases, litigation is particularly important for intermediate values of $b$. The direct and selection effects mentioned before explain why for low values of $b$ the patent holder has few chances in court, and so he 


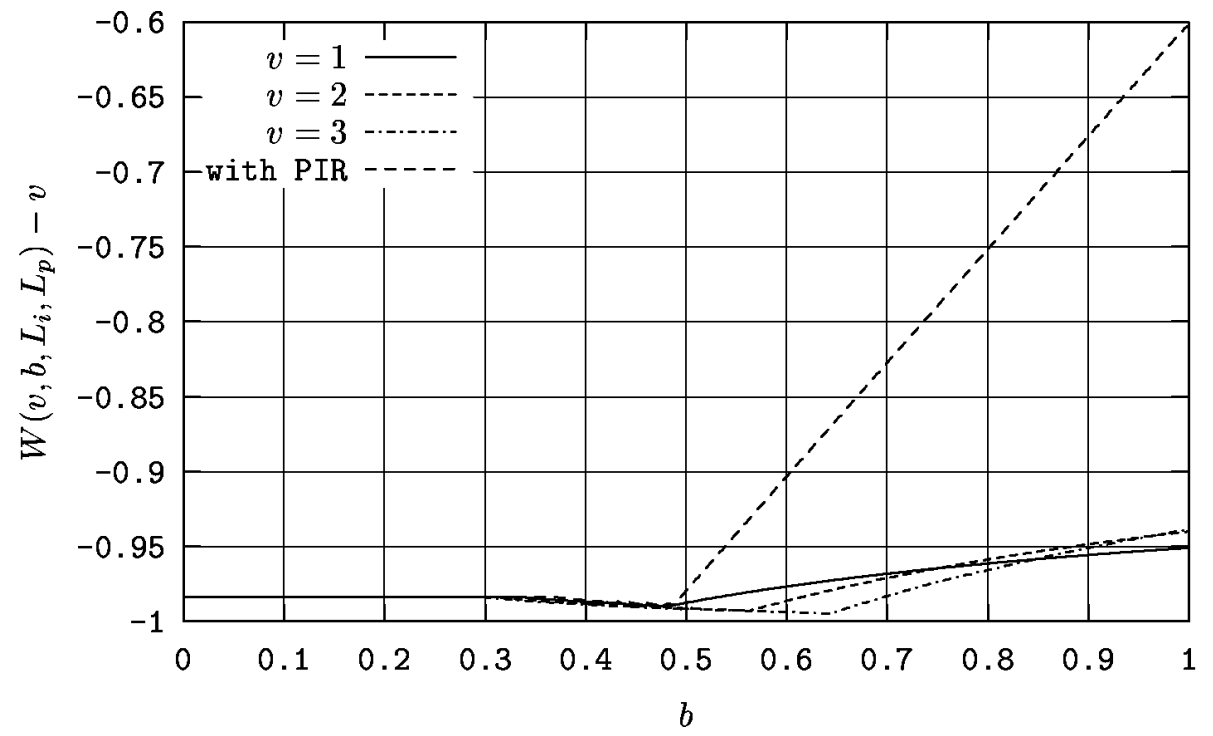

Figure 5: Decrease in profits obtained due to subsequent innovation with and without PIR. Notice that with PIR, as explained in Section 6.1, $W\left(v, b, L_{i}, L_{p}\right)-v$ does not depend on $v$.

decides to settle. On the other hand, when $b$ is high the patent holder deters entry more effectively. We also show that a Preliminary Injunctive Relief reduces litigation, while giving more incentives for entry to occur.

Figure 5 measures the reduction in profits - with and without PIR that the risk of infringement represents to the patent holder for different values of $v$, as $b$ increases. As pointed out before, in the benchmark case these profits are not monotonic in $b$ and are maximized when $b$ is either very low - and the patent holder obtains profits mainly from licensing or very high. Consistent with the previous figure, PIR results in higher profits due to the additional protection it represents.

We can also perform a welfare analysis in terms of the effects on future research. We use as a measure the sum of surplus achieved by consumers and producers in the market. In particular, without PIR, the social welfare generated through future innovation by a patent of value $v$, denoted by $S$ 


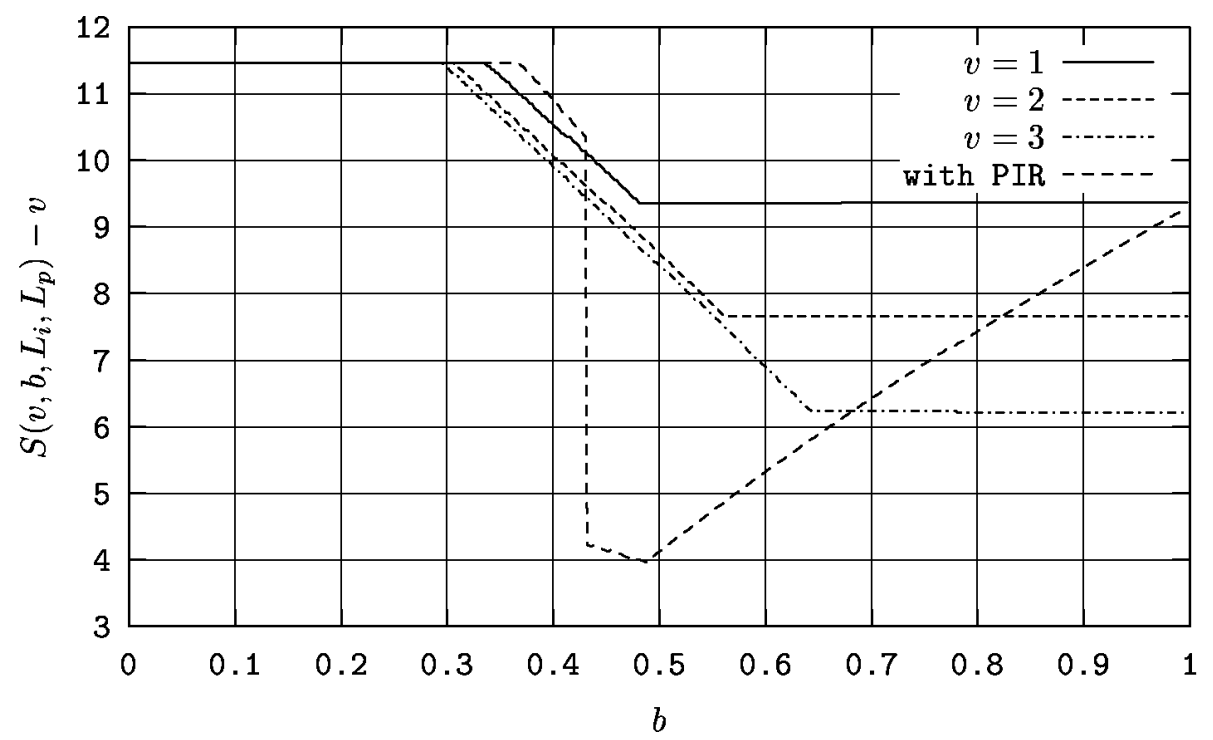

Figure 6: Increase in welfare due to the arrival of future innovation with and without PIR.

can be expressed as

$S\left(v, b, L_{i}, L_{p}\right)=\int_{\underline{\Delta}^{*}\left(v, b, L_{i}, L_{p}\right)} \Delta \phi(\Delta) d \Delta-\left(L_{i}+L_{p}\right)\left(1-\Phi\left(\Delta_{s}\left(v, b, L_{i}, L_{p}\right)\right)\right)$

while in the case with PIR, it becomes

$S_{P I R}\left(v, b, L_{i}, L_{p}\right)=\int_{\underline{\Delta}^{*}\left(v, b, L_{i}, L_{p}\right)}^{\Delta_{s}\left(v, b, L_{i}, L_{p}\right)} \Delta \phi(\Delta) d \Delta-\left(L_{i}+L_{p}\right)\left(1-\Phi\left(\Delta_{s}\left(v, b, L_{i}, L_{p}\right)\right)\right)$

The numerical results for different values of $b$ corresponding to a $v=$ 1,2 and 3 are provided in Figure 6 . They clearly show that the social welfare achieved with PIR is substantially lower when $v=1$ but this result changes when $v$ increases. Two effects need to be taken into account. When a PIR is requested consumers will not enjoy the future innovation while the process is resolved in court. At the same time, and because there will be less litigation, its social cost will decrease. The second effect is predominant when $v$ increases, as the quality of the patent represents a more important barrier to entry. 


\section{Concluding Remarks}

The goal of this paper was to study how the enforcement of Intellectual Property Rights affects the decisions to innovate. While other papers, such as Aoki and $\mathrm{Hu}$ (1999), have considered the effect of litigation on the value of patents, they usually study the trade-off that imitation constitutes between adding competition and the incentives to innovate. Nevertheless, patents also affect the decisions of future innovators. This paper tries to address this issue.

We have presented a model of patent settlement that takes explicitly into account the consequences of litigation, or the threat of using it. The results show that with private information on the quality of the new ideas there is in equilibrium a certain amount of litigation, together with the settlement of low quality innovations.

We stress the fact that the protection that patents grant is intimately related to the way in which it is enforced by courts. The outcome of the legal procedure is used by the patentee as a threat to obtain better terms in the negotiation with the infringer. However, more protection has a downside. The patentee cannot commit beforehand to offer a particular license, and therefore, as courts become more favorable to patentees, only the best infringers will enter. Because the patentee cannot distinguish among them, he might demand a lower licensing payment in order to avoid litigation.

Broader patents reduce the incentives for future innovators to appear and an important part of the value of a patent stems from licensing to them. Hence, more protection does not necessarily mean more profits for the patentee. This effect is particularly important on inventions that have a small value compared to the future stream of improvements they generate. In such a case, protection is shown to be always harmful.

By explicitly modeling the legal institutions, the model allows us to compare different legal systems. We perform two experiments. In the first, we study the consequences of a legal motion that has become pop- 
ular in recent years, the Preemptive Injunctive Relief. Its use seems to benefit relatively more better inventors that can demand higher licensing payments.

The second experiment consists on comparing the allocation of litigation costs under the American and the English rule. Although this sort of analysis has been common in general setups, here we are interested in the effects on innovation and settlement. The model predicts that under the English rule there will be less subsequent innovation but at the same time, there will be less litigation.

The answers provided in this paper are far from complete. We show that the effects of patent protection and litigation costs are more complex than what is usually considered. However, not much has been said about the socially optimal amount of protection. Preliminary results provide some insights in this direction and show that in some circumstances patents should discriminate among innovators. By granting less protection to worse inventors, the speed of innovation is increased leading to an increase in welfare.

\section{A Appendix: Proofs}

Here we reproduce the proofs of all the results in the paper.

\section{Lemma 1}

Proof. Given a menu of contracts $\{\alpha(\Delta), T(\Delta)\}$ the infringer will

declare the type $\widehat{\Delta}$ that maximizes profits. For a mechanism to be implementable, it must be that truthful revelation results in higher profits,

$$
\Delta \in \arg \max _{\widehat{\Delta}} \alpha(\widehat{\Delta})(v+\Delta)-T(\widehat{\Delta})-c .
$$

The standard sorting condition implies in this case that $\alpha$ is increasing in $\Delta$. Using the envelope condition on (15) and integrating with respect 
to $\Delta$ we obtain

$$
\pi_{i}^{s}\left(\Delta_{s}, b\right)-\pi_{i}^{s}(\Delta, b)=\int_{\Delta}^{\Delta_{s}} \alpha(y) d y
$$

and replacing $\pi_{i}^{s}\left(\Delta_{s}, b\right)$ for its expression in (3) we can solve for $T(\Delta)$ as

$$
T(\Delta)=\alpha(\Delta)(v+\Delta)-\pi_{i}^{l}(v, \Delta)+\int_{\Delta}^{\Delta_{s}} \alpha(y) d y .
$$

\section{Proposition 2}

Proof. Substituting $T(\Delta)$ in equation (5) and differentiating with respect to $\alpha(\Delta)$ the first order condition becomes,

$$
\frac{\Phi(\Delta)-\Phi(\underline{\widetilde{\Delta}})}{1-\Phi(\underline{\underline{\Delta}})}>0
$$

which means that the optimal contract involves $\alpha(\Delta)=1$ for all $\Delta \leq \Delta_{s}$.

The corresponding first order condition with respect to $\Delta_{s}$ is,

$$
\left(v+L_{i}+L_{p}\right) \phi\left(\Delta_{s}\right)-\frac{\partial q}{\partial \Delta}\left(\Delta_{s}, b\right) v\left[\Phi\left(\Delta_{s}\right)-\Phi(\underline{\widetilde{\Delta}})\right] \leq 0,
$$

with equality if $\Delta_{s}>\underline{\Delta}$. Checking the cross-derivatives we can show that $W$ is supermodular in $-\widetilde{\widetilde{\Delta}}$. Therefore, $\Delta_{s}$ is decreasing in $\widetilde{\Delta}$. The result follows from the definition of $T$.

\section{Proposition 3}

Proof. In the text. The only case not considered corresponds to $\underline{\Delta}$ bigger than the maximum size of idea. Trivially, this will constitute an equilibrium with no entry.

\section{Lemma 4}

Proof. The corresponding first order condition with respect to $\Delta_{s}$ is,

$$
\left(v+L_{i}+L_{p}\right) \phi\left(\Delta_{s}\right)-\frac{\partial q}{\partial \Delta}\left(\Delta_{s}, b\right) v\left[\Phi\left(\Delta_{s}\right)-\Phi(\underline{\widetilde{\Delta}})\right] \leq 0,
$$


with equality if $\Delta_{s}>\Delta$. Checking the cross-derivatives we can show that $\Delta_{s}$ is increasing in $L_{p}, L_{i}$ and $\widetilde{\Delta}$ and decreasing in $v$ and $b$. In particular for $v$, notice that if (16) is satisfied with inequality, the effect of changes in $v$ is null. However, if it holds with equality, we obtain that $\phi\left(\Delta_{s}\right)-\frac{\partial q}{\partial \Delta}\left(\Delta_{s}, b\right)\left[\Phi\left(\Delta_{s}\right)-\Phi(\underline{\underline{\widetilde{D}}})\right]<0$, which is enough to show using the Implicit Function Theorem that the effect of $v$ in $\Delta_{s}$ is negative.

Part (i) follows from the definition of $T$ and the results on $\Delta_{s}$ while (iii) can be directly observed from (11).

\section{Proposition 5}

Proof. As proven before, the unique pure strategy Sequential Equilibrium is determined by the $T^{*}$ and $\underline{\Delta}^{*}$ such that the following two conditions are satisfied:

$$
\begin{aligned}
T^{*} & =T\left(v, b, L_{i}, L_{p} \mid \underline{\Delta}^{*}\right), \\
\underline{\Delta}^{*} & =T^{*}-v+c .
\end{aligned}
$$

We show by contradiction that $T^{*}$ is increasing in $b$. Suppose not. Then there exists a set of parameters for which an increase in $b$ leads to a lower $T^{*}$. From equation (18) $\underline{\Delta}^{*}$ must also decrease. Since $\Delta_{s}$ is non-increasing in $b$ and increasing in $\underline{\Delta}$, it must be that $\Delta_{s}$ falls, and this can only happen if $T$ increases, leading to a contradiction. By the same argument, we obtain that $\underline{\Delta}^{*}$ must also increase in $b$. An identical proof is enough for the effect of $v$.

To show that $T^{*}$ is decreasing in $L_{p}$ we do it again by contradiction. Suppose that for some parameters $T$ increases in $L_{p}$. This implies that $\underline{\Delta}^{*}$ must also increase. Since $\Delta_{s}$ is increasing in $L_{p}$ and $\underline{\Delta}$, then $\Delta_{s}$ must also increase, leading to a lower $T$, which contradicts our premise.

For the last part, suppose that for some parameters $\underline{\Delta}^{*}$ is decreasing in $c$. This means that $\Delta_{s}$ must decrease and from (18) that $T$ is also decreasing in $c$. However, a lower $T$ implies that $\Delta_{s}$ must increase, leading to a contradiction. The rest of the implications are a direct consequence. 


\section{Lemma 6}

Proof. After some algebra we can obtain that

$$
\begin{aligned}
\frac{\partial W_{0}}{\partial b}= & \left(v-T^{*}\right) \phi\left(\underline{\Delta}^{*}\right) \frac{\partial \underline{\Delta}^{*}}{\partial b}-\frac{\partial W}{\partial b}=\left(v-T^{*}\right) \phi\left(\underline{\Delta}^{*}\right) \frac{\partial \underline{\Delta}^{*}}{\partial b}- \\
& -v\left\{\frac{\partial q}{\partial b}\left[\Phi\left(\Delta_{s}^{*}\right)-\Phi\left(\underline{\Delta}^{*}\right)\right]+\int_{\Delta_{s}^{*}} \frac{\partial q}{\partial b}(\Delta, b) \phi(\Delta) d \Delta\right\} .
\end{aligned}
$$

The first term is strictly negative, since $\frac{\partial \Delta}{\partial b}>0$ when $\frac{\partial^{2} q}{\partial \Delta \partial b}>0$ and $T=(2-q(\Delta, b)) v+L_{i}>v$. Hence, $\frac{\partial W_{0}}{\partial b}<0$ if $v$ is sufficiently small.

\section{Proposition 7}

Proof. The proof is almost identical to the one in Proposition 3. Notice, however, that in this case, the direct effect of $v$ on $\Delta_{s}$ is zero. Moreover, $\frac{\partial T}{\partial v}=1$, and so, changes in $v$ do not affect the level of entry, $\Delta^{*}$.

\section{Proposition 8}

Proof. Suppose that the winner pays an amount $L-\tau$ of the costs and the loser $L+\tau$. Since the American system corresponds to $\tau=0$ and the English is $\tau=L$, it is enough to prove that entry and litigation are decreasing in $\tau$.

The first order condition corresponding to the optimal value of $\Delta_{s}$ is independent of how the litigation costs are assigned, and it actually depends only on the sum. Therefore, the resulting $\Delta_{s}$ is obtained in (16). The license that makes such an infringer indifferent between accepting and rejecting the settlement satisfies for any $\tau$

$$
T=\left(1-2 q\left(\Delta_{s}, b\right)\right) v+\left(1-2 q\left(\Delta_{s}, b\right)\right) \tau-L .
$$

When $q\left(\Delta_{s}, b\right) \leq \frac{1}{2}, T$ is increasing in $\tau$ for a fixed $\widetilde{\Delta}$.

Since $\Delta_{s}$ is increasing in $\underline{\Delta}$, it is enough to show in the Sequential Equilibrium of the game $\underline{\Delta}^{*}$ is increasing in $\tau$. 
Suppose towards a contradiction that for some parameters the opposite is true. Then the optimal license $T^{*}=\underline{\Delta}+v-c$ is decreasing in $\tau$. Moreover the equilibrium cutoff value $\Delta_{s}^{*}$, would be decreasing in $\tau$, and from (19) this is a contradiction.

\section{B The Equilibrium when $\alpha=0$.}

The case where $\alpha=0$ is different from the rest. It is included for completeness, although it has some interesting features. One might think of this agreement as the patentee buying out the other firm.

The settlement offer that the patentee will make corresponds to a fixed amount $x$, (equivalent to $-T$ in the rest of the paper) that he will pay for the infringer to sell the invention and withdraw from the market. The offer will be accepted if $x \geq \pi_{i}^{l}(\Delta, v)$.

This equation leads to a cutoff value $\Delta_{s}$ such that only infringers with quality $\Delta>\Delta_{s}$ will go to court. It is important to notice that if the infringer expects the patentee to offer an amount $x>c$, she will enter regardless of her quality, since by staying out the profits obtained are zero. This means that the decision of the infringer is discontinuous in $x$. Due to this discontinuity, for any belief $\widetilde{\Delta}$ the patentee needs to compare the profits from $x \geq c$ to offering $x=0$, expecting to litigate all infringers. Therefore, the expression equivalent to equation (5) has now the form

$$
W=\max \left\{W_{x \geq c}(v, L \mid \underline{\underline{\Delta}}), W_{x=0}(v, L \mid \underline{\tilde{\Delta}})\right\},
$$

where

$$
\begin{aligned}
W_{x \geq c}(v, L \mid \underline{\widetilde{\Delta}})= & \max _{x} \int_{\widetilde{\underline{\Delta}}}^{\Delta_{s}}(v+\Delta-x) \phi(\Delta) d \Delta+ \\
& +\int_{\Delta_{s}}\left[R(v, \Delta)-L-\pi_{i}^{l}(\Delta, v)\right] \phi(\Delta) d \Delta, \\
W_{x=0}(v, L \mid \underline{\widetilde{\Delta}})= & \int_{\underline{\underline{\Delta}}}\left[R(v, \Delta)-L-\pi_{i}^{l}(\Delta, v)\right] \phi(\Delta) d \Delta .
\end{aligned}
$$


The next result shows that in fact the patentee will always offer $x>c$ and therefore, all infringers will enter. The reason is that regardless of $\widetilde{\Delta}$ the patentee will always decide to settle with the worse competitors.

Proposition 9 When $\alpha=0$, the Sequential Equilibrium of the game consists of $x>c$ and $\triangleq=0$.

Proof. Instead of solving equation (20) with respect to $x$, it is easier to solve for $\Delta_{s}$. The first order condition, can be expressed as

$$
(v+\Delta-R(v, \Delta)+L) \phi\left(\Delta_{s}\right)-\frac{\partial \pi_{i}^{l}}{\partial \Delta}\left(\Delta_{s}, v\right)\left[\Phi\left(\Delta_{s}\right)-\Phi(\underline{\widetilde{\Delta}})\right] \leq 0
$$

holding with equality when $\Delta_{s}>\underline{\widetilde{\Delta}}$. Notice that this expression cannot hold with an inequality, and therefore, either $x=0$ or $x>c$. This result rules out the case where $x=c$ and some infringers are indifferent between entering and staying out, and might randomize.

Now suppose towards a contraction that the patentee decides to offer $x=0$ (or any $x<c$ for that matter). In that case there would be no settlement, meaning that $\underline{\Delta}>0$ corresponds to the worse infringer that makes positive profits by going to court,

$$
\pi_{i}^{l}(\underline{\Delta}, v)-c=0 .
$$

Using this definition it follows that,

$$
v+\underline{\Delta}-c>R(v, \underline{\Delta})-L-\pi_{i}^{l}(\underline{\Delta}, v),
$$

and hence, there exists an $\varepsilon>0$ such that

$$
R(v, \underline{\Delta}+\varepsilon)-L-\pi_{i}^{l}(\underline{\Delta}+\varepsilon, v)<v+\underline{\Delta}+\varepsilon-x,
$$

where $x=\pi_{i}^{l}(\underline{\Delta}+\varepsilon, v)$. This implies that

$$
\begin{array}{r}
W_{x=0}(v, L \mid \underline{\Delta})=\int_{\underline{\Delta}}\left[R(v, \Delta)-L-\pi_{i}^{l}(\Delta, v)\right] \frac{\phi(\Delta)}{1-\Phi(\underline{\Delta})} \phi(\Delta) d \Delta \\
<\int_{\underline{\Delta}}^{\underline{\Delta}+\varepsilon}[v+\Delta-x] \frac{\phi(\Delta)}{1-\Phi(\underline{\Delta})} d \Delta+ \\
+\int_{\underline{\Delta}+\varepsilon}\left[R(v, \Delta)-L-\pi_{i}^{l}(\Delta, v)\right] \frac{\phi(\Delta)}{1-\Phi(\underline{\Delta})} d \Delta \leq W_{x \geq c}(v, L \mid \underline{\Delta}),
\end{array}
$$

and therefore, $x>c$ is preferred to $x=0$, leading to a contradiction. 


\section{References}

Aoki, R and J Hu (1999) 'Licensing vs Litigation: The effect of the legal system on incentives to innovate,' Journal of Economics \& Management Strategy, 8: 133-160.

Bebchuk L.A. and H.F. Chang (1994) 'An analysis of Fee-Shifting Based on the Margin of Victory: On Frivolous Suits, Meritorious Suits and the Role of Rule 11,' NBER Working Paper, No. 4731.

Chang, H.F. (1995) 'Patent Scope, antitrust policy and cumulative innovation,' RAND Journal of Economics, 26: 34-57.

Green, J. R. and S. Scotchmer (1995) 'On The Division of Profit in Sequential Innovation,' RAND Journal of Economics, 26: 20-33.

Lanjouw, J. (1994) ' Economic Consequences of a Changing Litigation Environment: The case of Patents,' NBER Working Paper No. 4835.

Lanjouw, J. and J. Lerner (1996) 'Preliminary Injunctive Relief: Theory and Evidence from Patent Litigation,' NBER Working Paper No. 5689.

Lanjouw, J. and J. Lerner (1997) 'The enforcement of Intellectual Property Rights: A Survey of the Empirical Literature,' NBER Working Paper No.6296.

Lanjouw, J. and M. Schankerman (1997) 'Stylized Facts of Patent Litigation: Value, Scope and Ownership,' NBER Working Paper No. 6297.

Lerner, J. (1994) 'The importance of patent scope: an empirical analysis,' RAND Journal of Economics, 25: 319-333.

Lerner, J. (1995) 'Patenting in the Shadow of Competitors,' Journal of Law and Economics, 38, pp.463-96. 
Llobet G., Hopenhayn H.A. and M. Mitchell (2000) 'Rewarding Sequential Innovations: Prizes, Patents and Buyouts,' CEMFI, .Working Paper 12-2000.

Meurer, M. (1989) 'The Settlement of Patent Litigation,' RAND Journal of Economics, 20: 77-91.

O'Donoghue T. S. Scotchmer and J. T. Thisse (1998) 'Patent Breadth, Patent Life and the Pace of Technological Progress,' Journal of Economics and Management Strategy, 7: 1-32.

Polinsky A.M. and D.L. Rubinfeld (1996) 'Optimal awards and penalties when the probability of prevailing varies among plaintiffs,' $R A N D$ Journal of Economics, 27: 269-280.

Reinganum J.F. and L.L Wilde (1986) 'Settlement, Litigation and the Allocation of Litigation Costs,' RAND Journal of Economics, 17: 557566 .

U.S. Patent and Trademark Office (1997) 'USPTO Annual Report 1997’.

Waldfogel, J. (1995) 'The Selection Hypothesis and the Relationship between Trial and Plaintiff Victory,' Journal of Political Economy, 103: 229-260.

Waterson, M. (1990) 'The Economics of Product Patents,' American Economic Review, 80: 860-869. 